\title{
CURRICULUM REFORM IN SOUTH AFRICA: A CRITICAL ANALYSIS OF OUTCOMES-BASED EDUCATION [1]
}

ABSTRACT Since South Africa's first national democratic elections in 1994, the Government of National Unity has issued several curriculum-related reforms intended to democratise education and eliminate inequalities in the post-apartheid education system. The most comprehensive of these reforms has been labelled outcomes-based education (OBE), an approach to education which underpins the new Curriculum 2005. While the anticipated positive effects of the new curriculum have been widely heralded, there has been little criticism of these proposals given the social and educational context of South African schools. In this article the philosophical, political and implementational dilemmas of OBE are systematically analysed and assessed.

\section{INTRODUCTION}

Since South Africa's first post-apartheid elections in April 1994, the Ministry of Education has introduced three national curriculum reform initiatives focussed on schools. The first attempt was to purge the apartheid curriculum (school syllabuses) of 'racially offensive and outdated content' (Jansen, 1997), while the second introduced continuous assessment into schools (Lucen et al., 1988). However, the most ambitious curriculum policy since the installation of a Government of National Unity has been referred to as outcomes-based education (OBE). This article offers a critical assessment of the claims, assumptions and silences underpinning official policy on OBE. In the process, I intend to demonstrate how the current status of education in South Africa militates against sophisticated curriculum reforms such as OBE. In concluding, I will argue that it is important to understand the origins and anticipated trajectory of OBE (and indeed other curriculum reforms) as primarily a political response to apartheid schooling, rather than one which is concerned with the modalities of change at the classroom level.

\section{BACKGROUND}

With great fanfare, culminating in the release of 2005 multi-coloured balloons, the Minister of Education launched Curriculum 2005 in Cape Town on 24 March 1997.

Leading up to this event, schools and their allies had been repeatedly warned by the National Department of Education that January 1998 was an 'absolutely non-negotiable' date for the implementation of what has only recently become known as OBE. Within months, an explosion of curriculum activity thundered across South Africa as committees of departmental officials, curriculum developers, subject specialists, teachers, lecturers, trade union and business representatives and a good representation of foreign 'observers' from Scotland to Australia attempted to translate OBE into 
workable units of information for teaching and learning which would be ready for first phase implementation in 1998.

At first glance, there appear to be sound reasons for a curriculum policy modelled on OBE. Outcomes would displace an emphasis on content coverage. Outcomes make explicit what learners should attend to. Outcomes direct assessment towards specified goals. Outcomes signal what is worth learning in a content-heavy curriculum. Outcomes can be a measure of accountability, i.e. a means of evaluating the quality and impact of teaching in a specific school. These are universal claims associated with OBE in several first-world countries. Yet there are several problems documented regarding the OBE experience in these countries. Do outcomes in fact deliver what they claim? How do outcomes play out in a resource-poor context? Can outcomes survive their psychological roots in behaviourism? Do outcomes in different contexts mean the same thing, e.g. are outcomes specified for education equivalent to those identified for training? These are some of the questions addressed in this comprehensive criticism of OBE using as reference points the current status of South African schools, experiences of other countries with OBE and, more broadly, important philosophical arguments against an outcomes-based approach to education.

OBE does not have any single historical legacy. Some trace its roots to behavioural psychology associated with B.F. Skinner; others to mastery learning as espoused by Benjamin Bloom; some associate OBE with the curriculum objectives of Ralph Tyler; yet another claim is that OBE derives from the competency education models associated with vocational education in the UK (Mahomed, 1996). In South Africa, the most immediate origins of OBE are in the competency debates followed in Australia and New Zealand (Christie, 1995), which animated training and development discussions in the Congress of South African Trade Unions (COSATU), which eventually appeared in documents of the National Training Board (such as the National Training Strategy Initiative) and, subsequently, crystallised in the National Qualifications Framework (NQF). It was largely the result of deliberations within the NQF to integrate education and training that the debate on competencies was extended to education. More recently, 'competencies' was reframed as 'outcomes' in the Department of Education. This history is important because it partly explains the growing disaffection with OBE in the education community, given the very recent exposure to this policy in schools and the absence of a sustained debate about OBE among teachers and educators. It also explains the parameters of the criticism which follows.

\section{PRINCIPAL CRITICISMS OF OBE}

In this article I outline 10 major reasons why OBE will have a negative impact upon South African schools. My thesis is that OBE will fail, not because politicians and bureaucrats are misinformed about conditions of South African schooling, but because this policy is being driven in the first instance by political imperatives which have little to do with the realities of classroom life. Rather than spawn innovation, OBE will in fact undermine the already fragile learning environment in schools and classrooms of the new South Africa. 
First, the language of innovation associated with OBE is too complex, confusing and at times contradictory. A teacher attempting to make sense of OBE will not only have to come to terms with more than 50 different concepts and labels but also keep track of the changes in meaning and priorities afforded to these different labels over time. For example, to understand the concept of 'outcomes' requires understanding of competencies, unit standards, learning programmes, curriculum, assessment criteria, range statements, equivalence, articulation, bands, levels, phases, curriculum frameworks and their relationship to the South African Qualifications Authority (SAQA), the NQF, National Standards Bodies (NSBs), Standards Generating Bodies (SGBs) and Education and Training Qualification Agencies (ETQAs), reconciliation of the 12 SAQA fields with the eight learning areas with the eight phases and the fields of study, and on and on. But it also requires understanding the sudden shift from 'competencies' to 'outcomes' in the official discourse on OBE, what lies behind the change and how the two terms now relate within the new policy. The only certainty about OBE and its predecessor language is that it has constantly changed meaning. This language is quite simply inaccessible. So, for example, essential outcomes are distinguished in most policy papers from specific outcomes whilst the former has recently been displaced by 'critical outcomes'. Having been there from the beginning, i.e. when COSATU first proposed competency-based education in the early 1990s, an idea taken up in the National Training Board and transferred into the Department of Education as official discourse, I still find the maze of jargon and tortured definitions intimidating. For this reason alone, the language of OBE and its associated structures are simply too complex and inaccessible for most teachers to give these policies meaning through their classroom practices.

Second, OBE as curriculum policy is implicated in problematical claims and assumptions about the relationship between curriculum and society. Among advocates, OBE policy claims in South Africa are either associated with, stated as prerequisite for or sometimes offered as a solution to economic growth. Consider the following:

South Africa's inability to generate an economic growth rate to sustain all of its redress needs is largely due to the lack of relevant skills ... [the] present education and training system is designed to meet the needs of an outdated and narrowly Taylorist specification and this renders the economy incapable of competing with workforces that are trained to be 'self-directed, innovative and reflective'. (Mahomed, 1996; following Tyers, 1996)

It is believed that the economy must grow at approximately $6 \%$ in order to create sufficient jobs to drastically reduce unemployment levels in the country, i.e. to absorb school leavers and the present unemployed. South Africa's economy is however growing at a rate which is around $3 \%$. In order to change this the transformation of the Labour Market is seen as being a step in the creation of growth. This would require a clear change in the nature of the South African education system. Hence the move towards an outcomesbased approach to education. (Department of Education, undated a) 
Allied to the vision of South Africa as a prosperous ... internationally competitive country, is a vision of its people as literate and productive human beings. (Department of Education, undated $b$ )

Equally OBE is argued as facilitating human resources development and potentially contributing to a vibrant economy. (National Curriculum Development Committee, 1996)

There is not shred of evidence in almost 80 years of curriculum change literature to suggest that altering the curriculum of schools leads to or is associated with changes in national economies. Even the most optimistic of studies, conducted in Tanzania and Colombia by the World Bank, suggest that there is simply no evidence from experimental research that curriculum diversification, i.e. an attempt to make curriculum responsive to economic conditions, has 'significant' social or private benefits (Psacharopoulos \& Woodhall, 1986, pp. 60-64 and 229-235). This is particularly the case in developing countries, where economic problems have little to do with what happens inside schools and much more to do with the economics and politics of a third-world state, e.g. sustained high unemployment (Camoy \& Samoff, 1990). What official documents therefore claim is at best misleading since they offer an economic development panacea to benefit those alienated from education and training under apartheid in the name of a complex curriculum reform policy. To make such connections between curriculum and society has understandable political goals, but these connections have no foundation in the accumulated research on curriculum change.

Not only does OBE offer a proposed solution to economic problems, it is also sold as a solution to universal and deeply entrenched pedagogical problems. Consider these claims in the popular version of NQF/OBE policy under the caption 'Let's find out more about Outcomes':

In the old education system only the content of the courses and what the teacher or the textbook had to say was important. Learners received information from the teacher and did not play a very active role in the learning situation. Most of their learning was memorybased. Learners were seldom given the opportunity to show what they learned and how to use their knowledge. It was important that learners remembered and repeated everything they learned, and not whether they understood and were able to use what they had learned in different ways or situations. (Education Information Centre, 1996, p. 12)

Departmental documents are equally ambitious with respect to the changing demands made on the teacher under OBE:

Current learning institutions place the teacher in a particular role. The teacher is seen to be in a position of authority to the learner and an authority in terms of content which must be transmitted.... The teacher, as opposed to being the repository of all knowledge and wisdom, must now facilitate and mediate the educational experience. ... The teacher, now a facilitator of learning, will create relations between learners and facilitator which engender values based 
on cooperative learning. ... The teaching and learning strategies which will mediate the learning are the responsibility of the teacher and must reflect the learning outcome. (Department of Education, undated a, pp. 12-13)

Such claims represent a conceptual leap of staggering proportions from outcomes to dramatic changes in social relations in the classroom. How will this happen? It is such an over-sell of OBE policy, which not only misguides and misinforms teachers and the public, that it undermines the authenticity of the policy itself.

Third, OBE is destined to fail in the South African education system because it is based on flawed assumptions about what happens inside schools, how classrooms are organised and what kinds of teachers exist within the system. The claims that 'transformational OBE ... is a collaborative, flexible, transdisciplinary, outcomes-based, open-system, empowerment-oriented approach to learning' (National Curriculum Development Committee, 1996, p. 7) suggests that highly qualified teachers exist to make sense of such a challenge (let alone the terminology) to existing practice. The policy requires not merely the application of a skill, but an understanding of its theoretical underpinnings and demonstration of a capacity to transfer such application and understanding across different contexts. Anyone who seriously believes that such an innovation will be 'implemented' with these original insights in mind has not spent enough time inside the average South African classroom. As Vithal (1997) correctly argues in a submission to the Association of Mathematics Educators in South Africa (AMESA):

In mathematics education in South Africa there is arguably a tradition of defining narrow behavioural objectives derived from the content mathematics teachers are expected to teach. So how are 'outcomes' different from 'objectives'? Even if the policy intends a 'transformational' OBE that moves away from a 'transformational' OBE, how will it counter the implementation of such a model from degenerating into specifying and teaching narrow mathematical techniques and procedures in ways that teachers have been doing all along? (pp. 1-2)

It is against this background that an alternative scenario to that envisaged by the Department of Education seems inevitable: that OBE will be implemented in 1998 in most provinces regardless of the calls of teachers for more time and training; that the drive towards detailing 'specific outcomes' will become an exercise reminiscent of the 1970s 'objectives movement', where the outcomes become the focus of over-specification, i.e. hundreds of little objectives being defined in an attempt to be precise about what is meant; that these outcomes are then taken by teachers (both qualified and underqualified) to be the ends of education and, therefore, the focus of assessment; that teachers then teach towards the minutiae of outcomes or objectives, with a reinforcing backwash effect from the assessment system; that what started off as an enlightened model of 'transformational competencies' will become a mechanical model of behaviourism in the majority of South African schools and classrooms. Such a scenario, I would argue, is inescapable, especially 
since there is no sustained intervention at the classroom level in the lead up to OBE 1998 to counter this possibility effectively.

Fourth, there are strong philosophical reasons for questioning the desirability of OBE in democratic school systems. One need not take the radical but enticing position that specifying outcomes in advance might be antidemocratic. It is sufficient to argue that this policy offers an instrumentalist view of knowledge, a 'means-ends OBE stance ... that violates the epistemology of the structure of certain subjects and disciplines' (McKernan, 1994, p. 2). Developing technical writing skills or the mechanical repair of a bicycle tube lends itself to specifying instrumental outcomes; developing appreciation for a complex reading in English literature or poetry does not. Richard Peters (1966) makes a persuasive argument that 'worthwhile activities have their own built-in standards of excellence, and therefore they can be evaluated according to the standards inherent in them rather than according to some end or outcome' (in McKernan, 1994, p. 2). And there is a fundamental contradiction in insisting that students use knowledge creatively only to inform them that the desired learning outcomes are already specified (Kanpol, 1995).

Fifth, there are important political and epistemological objections to OBE as curriculum policy. The question must be asked again of the African National Congress (majority party in the Government of National Unity) and its democratically aligned partners: how is it that a movement which predicated its politics on the notion of process organises its policies on a platform of 'outcomes'? There is something fundamentally questionable about a focus on ends as final outcomes when much of the educational and political struggle of the 1980s valued the processes of learning and teaching as ends in themselves. This problem extends to the manner in which teachers as a constituency have been limited in their participation around this important policy. A small elite of teachers, often expert and white, have driven the Learning Area Committees and other structures in which OBE has been developed. The sad reality is that the overwhelming majority of teachers simply do not have access to information on OBE or understand OBE in instances where such information may be available. In other words, there is not a process, systematic and on-going, in which teachers are allowed to conceptualise and make sense of OBE as curriculum policy. In a cruel twist of history, teachers continue to be defined as 'implementers' and even in this marginal role, official support is uneven, fragmented and, for many teachers, simply non-existent.

Sixth, OBE with its focus on instrumentalism--what a student can demonstrate given a particular set of outcomes--sidesteps the important issue of values in the curriculum. Put more directly, OBE enables policy makers to avoid dealing with a central question in the South African transition, namely what is education for? For example, there is little evidence in the report of the Learning Area Committee for Human and Social Sciences that this question has been directly addressed (September et al., 1996). One would expect in this Committee that core values and commitments would be more readily evident than, for example, in the natural sciences. Yet there is not a single 
commitment to combatting racism and sexism in society or developing the Pan-African citizen or on the role of dissent in a democracy. Of the 17 learning area outcomes identified, the closest approximation to a value statement is the phrase 'participate actively in promoting a sustainable, just and equitable society', a statement so broad as to become meaningless, especially when this is unpacked in specific objectives such as 'display constructive attitudes' or 'participate in debate and decision-making'. These statements could have been written for Hawaii or Buenos Aires or Western Nigeria. They are bland and decontextualised global statements which will make very little difference in a society emerging from apartheid and colonialism. Furthermore, OBE as outcomes does not define content, what policy bureaucrats call the actual learning programmes. As a result, the same set of learning outcomes could be exposed to a wide range of interpretations by teachers; this means, for example, that outcomes with good citizenship goals could mean one thing in a conservative school setting and another in a school with a broad democratic ethos (see elaboration later). There is nothing within the OBE framework to prevent such a latitude of interpretation that would mute even the modest directions signalled in an outcome.

Seventh, the management of OBE will multiply the administrative burdens placed on teachers. A useful example of such trends is found in recent research on how teachers understand and implement continuous assessment, a policy instructive issued to all schools in the wake of the syllabus reform process spearheaded by the National Education and Training Forum in 199411995. Rather than encourage a more progressive, holistic assessment of students as the policy stipulated, continuous assessment in practice meant little more than assessing continuously in most schools (Lucen et al., 1997). The range of assessment tasks remained more or less constant; however, the number of tasks multiplied significantly. The same is likely to happen with OBE. To manage this innovation teachers will be required to reorganise the curriculum, increase the amount of time allocated to monitoring individual student progress against outcomes, administer appropriate forms of assessment and maintain comprehensive records. As experienced elsewhere (Schwartz \& Cavener, 1994), OBE fails in the absence of adequate support such as 'release time, aide support, smaller class sizes ...' (Brady, 1996, p. 13). With current policies of teacher rationalisation and the directive to increase average class sizes, OBE enters an environment which directly mitigates against the conditions for its success.

Eighth, OBE trivialises curriculum content even as it claims to be a potential leverage away from the content coverage which besets the current education system. Children do not learn outcomes in a vacuum. Curriculum content is a critical vehicle for giving meaning to a particular set of outcomes. An outcome such as 'appreciating the richness of national and cultural heritages' (Learning Area Committee: Human and Social Sciences) could be based on content which glorifies a narrow Afrikaner nationalism but also valorises, in another context, a militant ethnic Africanism. Content matters. A fixation with outcomes could easily lead to serious losses with respect to building a multicultural curriculum which both moves beyond ethnicity while simultaneously engaging with the historicity of such concepts and ideals in the 
context of apartheid South Africa. But selecting curriculum content implies choice, and this is where the politics of curriculum reform coincides with the broader politics of transition. Who makes those choices, where and under what conditions? It is crucial, therefore, for OBE evangelicals not to renege on a commitment to making strategic curriculum choices which would form the basis for the critical outcomes which underpin a new curriculum. But OBE trivialises content in another way: it threatens to atomise and fragment curriculum knowledge. By organising knowledge around discrete competences, OBE overlooks the important cross-curricular and interdisciplinary demands encountered in learning a complex task. It further assumes that knowledge acquisition proceeds in a linear way such that one outcome is linked in a stepwise direction to another. This is one of the most common criticisms made of OBE and yet it appears to be ignored in the move towards implementation (Holland, 1990).

Ninth, for OBE to succeed even in moderate terms a number of interdependent innovations must strike the new educational system simultaneously. It requires trained and retrained teachers, radically new forms of assessment (such as performance assessment or competency-based assessment), classroom organisation which facilitates monitoring and assessment, additional time for managing this complex process, constant monitoring and evaluation of the implementation process, retrained education managers or principals to secure implementation as required, parental support and involvement, new forms of learning resources (textbooks and other aides) which are consonant with an outcomes-based orientation and opportunities for teacher dialogue and exchange as teachers co-learn in the process of implementation. In other words, an entire re-engineering of the education system is required to support the innovation. There is neither the fiscal base nor the political will to intervene in the education system at this level of intensity. Yet nothing less is required to give the policy a reasonable chance of success.

Tenth, as suggested earlier, OBE requires a radical revision of the most potent mechanism in schools militating against curriculum innovation, namely the system of assessment. It is striking, for example, that the policy of continuous assessment was not allowed to be introduced at standard 10 (the final year of formal schooling) because of the powerful interests insisting on the assessment status quo with respect to the matriculation examination. Unsurprisingly, the international experience with OBE suggests that assessment changes only moderately with an outcomes-based innovation. In the USA, where human and material sources for innovation are generally available:

Few schools appear to have actually reorganised their curriculum and overhauled their assessment and reporting schemes to reflect new, higher outcomes. More commonly, schools and districts draft outcomes based on the present curriculum or write ambitious and farreaching new outcomes while changing the curriculum very little. (Brandt, 1994, p. 3)

Even supporters of OBE in the same country caution that: 
Given their complexity, outcome-based performance tasks probably cannot be used very frequently by classroom teachers; thus, they will probably not totally replace more traditional assessments ... much research is needed to determine the validity of outcome-based performance tasks and the conditions under which high inter-rarer reliabilities can be guaranteed. (Marzano, 1994, p. 6)

The fact that the hurried discussions in the Learning Area Committees in South Africa are not accompanied by intensive debates about the reorganisation of the assessment system means that the traditional examinations will continue to play a powerful role in shaping the nature of OBE-directed teaching and learning, reinforcing the curriculum status quo, as was evident in the local experience with continuous assessment.

In conclusion, how does one explain these dilemmas of OBE as outlined in the policy criticism offered? I propose two levels of analysis, technical and political, equally valid.

From a technical perspective, it could simply be argued that the prerequisites for fundamentally changing the apartheid curriculum are not in place. Indeed, OBE as a curriculum innovation has not taken adequate account of the resource status of schools and classrooms in South Africa. OBE as policy is not grounded in the curriculum change experiences of other countries with similar initiatives. Moreover, OBE will further undermine the already weak culture of teaching and learning in South African schools by escalating the administrative burden of change at the very time that rationalisation further limits the human resource capacity for managing such change. The longer term effects of $\mathrm{OBE}$ are also unavoidable, namely that the more schools are loaded with unworkable innovations, the less likely they are to adopt such changes in the future. The weak reception of continuous assessment (1995/96) in schools and the complete ineffectiveness of the syllabus revision process (1994/95) in changing curriculum practice should have sounded alarm bells among planners and policy makers. On simple technical grounds, therefore, OBE as a national curriculum initiative is likely to fail.

From a political perspective, it is important to understand OBE as an act of political symbolism in which the primary preoccupation of the state is with its own legitimacy. The proliferation of Green and White Papers, and corresponding Bills and Acts, has not been matched by visible changes in the schools. Earlier research has demonstrated that the national syllabus revision process (1995) was driven almost exclusively by official attempts to demonstrate to constituencies that at least some action was forthcoming from the Ministry of Education in the period immediately following the elections (Jansen, 1997). Similarly, OBE is primarily an attempt to push forward something innovative into the schools at all costs in order to reclaim political credibility for a Ministry of Education which is still charged, within and outside of government, with having delivered little concrete evidence of transformation in the schools. Not a single official interviewed in the Department of National Education believed that OBE should be introduced so soon, yet they all work feverishly towards implementation at all costs in 1998. There is no other way 
of understanding such behaviour outside of a political analysis of state and curriculum in the South African transition (Jansen, 1995).

Correspondence: Jonathan D. Jansen, Faculty of Education, University of Durban Westville, Private Bag X54001, Durban 4000, South Africa. E-mail: jjansen@pixie.udw.ac.za

\section{NOTES}

[1] An earlier version of this article, entitled Why OBE will Fail, was presented at a National Conference on outcomes-based education held at the University of Durban Westville in March 1997. I am grateful to Renuka Vithal and Ben Parker for critical comments on the original paper.

\section{REFERENCES}

BRADY, L. (1996) Outcome-based education: a critique, The Curriculum Journal, 7(1), pp. 5-16.

BRANDT, R. (1994) Aiming for new outcomes: the promise and reality, Educational Leadership, 5, pp. 6-10.

CARNOY, M. \& SAMOFF, J. (1990) Education and Social Transition in the Third World (Princeton, NJ, Princeton University Press).

CHRISTIE, P. (1995) Global trends in local contexts: a South African perspective on competency debates, unpublished paper, University of the Witwatersrand, Johannesburg.

DEPARTMENT OF EDUCATION (Undated a) An Outcomes-Based Approach to Educational and Curriculum Development in South Africa, unofficial document (Pretoria, Department of Education).

DEPARTMENT OF EDUCATION (Undated b) A Pre-Implementation Strategy for Phasing-In New Learning Programmes in General and Further Education and Training (Pretoria, Department of Education).

EDUCATION INFORMATION CENTRE (1996) Understanding the National Qualifications Framework: a guide for lifelong learning (Pietermaritzburg, Interpak Books).

HOLLAND, D. (1994) ABE assessments for levels I and 2: a summary paper for the Independent Examinations Board, unpublished report (Johannesburg, Independent Examinations Board).

JANSEN, J.D. (1995) Understanding social transition through the lens of curriculum policy, Journal of Curriculum Studies, 27, pp. 245-261.

JANSEN, J.D. (1997) 'Essential alterations?' A critical analysis of the states syllabus revision process, Perspectives in Education, 17(2), pp. 1-11. 
KANPOL, B. (1995) Outcome-based education and democratic commitment: hopes and possibilities, Educational Policy, 9, pp. 359-374.

LUCEN, A. \& RAMSURAN, A. (1997) Interim findings of research on continuous assessment in KwaZulu Natal high schools, Masters Degree dissertations, University of Durban Westville.

MAHOMED, N. (1996) Competence: past debates and future problems, EPU Working Paper No. 10 (Durban, University of Natal/Durban).

MARZANO, R. (1994) Lessons from the field about outcome-based performance assessments, Educational Leadership, 51, pp. 44-50.

MCKERNAN, J. (1994) Some limitations of outcome-based education, Journal of Curriculum and Supervision, 8(4), pp. 343353.

NATIONAL CURRICULUM DEVELOPMENT COMMITTEE (1996) A Framework for Life-Long Learning (Pretoria, Department of Education).

PSCAHAROPOULOS, G. \& WOODHALL, M. (1985) Education for Development: an analysis of investment choices (Washington, DC, World Bank).

SCHWARZ, G. \& CAVENER, I,.A. (1994) Outcome-based education and curriculum change: advocacy, practice and critique, Journal of Curriculum and Supervision, 9, pp. 326-338.

PETERS, R. (1966) Ethics and Education (London, George Allen and Unwin).

SEPTEMBER, J. (1996) Learning Area Committee Report: human and social sciences (Natal, University of Natal, Education Policy Unit).

TYERS, J. (1996) Competence--a South African perspective, paper presented at the Education, Training and Development Workshop, Report of the Proceedings for the Committee on South African Trade (Pretoria, Department of Education).

VITHAI., R. (1997) A Response to the Positions and Recommendations of the AMESA Curriculum Committee (Durban, University of Durban Westville, Faculty of Education). 